\title{
Adequação das Chamadas Públicas para Aquisiçã̃o de Produtos da Agricultura Familiar para a Alimentação Escolar
}

\author{
Rozane Marcia Triches ${ }^{1}$ \\ Fernanda Silvestri ${ }^{2}$ \\ http://dx.doi.org/10.21527/2237-6453.2018.44.233-259 \\ Recebido em: 17/2/2017 \\ Aceito em: 1。/9/2017
}

\section{Resumo}

Um dos mais recentes avanços do Programa Nacional de Alimentação Escolar foi a criação da Lei o. 11.947/2009, a qual garante que sejam investidos no mínimo 30\% dos recursos para compra de produtos da agricultura familiar (AF). Este estudo tem por objetivo verificar até que ponto as chamadas públicas (CPs), realizadas por prefeituras municipais do Estado do Paraná, se mostram adequadas em relação ao público que pretendem alcançar e o quanto seu objetivo é atingido no que se refere à compra efetiva quando comparada aos produtos que solicita. Trata-se de uma pesquisa de caráter quantitativo realizado pelas análises das chamadas públicas e as prestações de contas de municípios do Estado do Paraná no ano de 2013. Verificou-se que, em relação aos recursos provindos do Fundo Nacional de Desenvolvimento da Educação (FNDE), cerca de 70\% dos municípios destinam 30\% ou mais para a compra de produtos da agricultura familiar. A demanda de produtos que constava nas chamadas públicas dos municípios analisados, no entanto, não foi efetivada totalmente. Do total remetido pelo FNDE aos municípios pesquisados, $22 \%$ foi direcionado à aquisição de produtos da agricultura familiar via chamada pública, mas apenas $12,52 \%$ foram realmente pagos aos agricultores. Neste sentido, este estudo evidenciou problemas relativos às chamadas públicas, como a falta de preço dos produtos (em 7\%), logística (em 21\%) e periodicidade de entrega (em 93\%), prejudicando sua eficiência como instrumento de aquisição pública, dificultando, assim, que o PNAE alcance seus objetivos de promover alimentação adequada e desenvolvimento sustentável.

Palavras-chave: Alimentação escolar. Agricultura familiar. Segurança alimentar e nutricional. Aquisições públicas.

\footnotetext{
1 Doutora em Desenvolvimento Rural e mestre em Epidemiologia pela Universidade Federal do Rio Grande do Sul (UFRGS). Graduada em Nutrição pela Universidade Regional do Noroeste do Estado do Rio Grande do Sul (Unijuí). Professora da Universidade Federal da Fronteira Sul-PR (UFFS). rozane. triches@gmail.com

2 Graduada em Nutrição pela Universidade Federal da Fronteira Sul-PR. fernandasilvestri@hotmail.com
} 


\title{
ADEQUACY OF PUBLIC CALLS FOR ACQUISITION OF FAMILY AGRICULTURE PRODUCTS FOR SCHOOL FEEDING
}

\begin{abstract}
The National School Feeding Program is aimed at the supply of adequate food for schoolchildren of all Brazil. One of his most recent developments has been the creation of law no 11.947/2009, which ensures they are invested at least $30 \%$ of the resources for purchase of small farming products (AF). This study aims to verify to what extent the public calls (CPs) performed by municipal administrations of Paraná State are appropriate in relation to the public who wish to accomplish and how much your goal is reached when it comes to purchasing effective when compared to products which requests. It is a quantitative character research conducted through the analysis of the public accounts and calls of municipalities in the State of Paraná in the year 2013. It was found that, in relation to the resources coming from Fundo Nacional de Desenvolvimento da Educação (FNDE), about $70 \%$ of the municipalities are for $30 \%$ or more for the purchase of small farming products. However, the demand for products that were in the public call the cities analysed was not fully effective. Of the total shipped by FNDE to municipalities surveyed, $22 \%$ was directed to the acquisition of small farming products via public call, but only $12.52 \%$ was actually paid to farmers. Thus, this study highlighted several issues, relating to public calls, such as the lack of price of products (in 7\%), logistics (in 21\%) and delivery frequency (in 93\%), damaging your efficiency as an instrument of public procurement, making the PNAE reach their goals of promoting an appropriate power supply and sustainable development.
\end{abstract}

Keywords: School feeding. Family farming. Food and nutrition security. Public procurement. 
O Programa Nacional de Alimentação Escolar (PNAE) existe há mais de 60 anos (criado em 1955) e é um dos poucos programas alimentares com atendimento universalizado. Passou a ser um direito social de todas as crianças e adolescentes que frequentam a escola a partir da Constituição Federal de 1988 (BRASIL, 2009; TRICHES; SCHNEIDER, 2010). Em 2015 atendeu cerca de 41,5 milhões de alunos, e investiu, só de recursos federais, em torno de 3,759 bilhões de reais para a compra de alimentos (BRASIL, 2016).

Durante a sua existência, o PNAE passou por diversas reestruturações que levaram a avanços, dos quais um dos mais importantes é o apoio ao desenvolvimento sustentável, com incentivo para a aquisição de gêneros alimentícios diversificados, produzidos em âmbito local por agricultores familiares com respeito aos hábitos alimentares saudáveis e regionais (VILAR et al., 2013). Nesse sentido, uma das estratégias da Lei ${ }^{\circ}$ 11.947/2009 para o cumprimento dos termos citados anteriormente, pode ser evidenciada no artigo 14, que dita que, do total dos recursos financeiros repassados pelo Fundo Nacional de Desenvolvimento da Educação (FNDE) para as Entidades Executoras (EEs), no mínimo 30\% deverá ser destinado à aquisição de gêneros alimentícios provenientes da agricultura familiar e do empreendedor familiar rural, ou até mesmo de suas organizações, dando prioridade aos assentamentos da reforma agrária e comunidades indígenas e quilombolas (BRASIL, 2009). Para efetivar este propósito, o processo das aquisições públicas para a alimentação escolar foi repensado e adaptado a este fornecedor em particular - o Agricultor Familiar. Assim, as compras realizadas poderiam ser feitas dispensando-se o processo licitatório, a partir de Chamadas Públicas (CPs).

Estudos realizados (BELIK; CHAIM, 2009; TURPIN, 2009, TRICHES et al., 2014) indicam que a compra de produtos da agricultura familiar para o PNAE tem demonstrado potencialidades no que diz respeito aos consumidores, indicando aumento na disponibilidade e na quantidade de alimentos de qualidade nutricional superior, como frutas, verduras e legumes, e a valorização de produtos da cultura alimentar da região, o que providenciaria mudanças nas práticas alimentares e concepções das crianças. Além 
disso, tem sido um dos espaços privilegiados para possibilitar a construção social de mercados alternativos, fomentando renda e ampliação da comercialização dos produtos de agricultores familiares. Na esteira desta experiência brasileira, países como a Itália, Escócia, Tailândia, Japão, Gana, Nigéria e Estados Unidos, têm adotado iniciativas visando a aproximar a produção e o consumo de alimentos em âmbito escolar, por meio da compra com agricultores familiares locais. Essas ações são focadas tanto no encurtamento da cadeia produtiva de alimentos, na sustentabilidade e no desenvolvimento rural, quanto também na aproximação com os hábitos alimentares do local e melhoria da qualidade da refeição servida (MORGAN; SONNINO, 2007; WORLD..., 2009; IZUMI; ALAIMO; HAMM, 2010; TRICHES; SCHNEIDER, 2010; SOARES et al., 2013).

Não obstante a estes resultados, o novo modelo de compras públicas adotado pelo Brasil, no caso do PNAE, ainda está em fase de aprimoramento, posto que outras dificuldades foram criadas, além do que as barreiras de entrada e altos custos de transação para o agricultor familiar nos mercados formais, ainda persistem (ROZENDO; BASTOS; MOLINA, 2014; SOUZA, 2012; BACCARIN et al., 2011; SARAIVA et al., 2013).

Neste contexto, poucos estudos têm avaliado a eficiência das CPs na efetivação desta política. Argumenta-se que a realização de pesquisas que avaliem a eficiência, eficácia e a efetividade do PNAE, considerando sua potencialidade na área de abastecimento alimentar, com base no fortalecimento da agricultura familiar, da agroecologia e da agroindústria familiar, são de grande importância, visando o seu aprimoramento. Por isso, este estudo tem por objetivo verificar até que ponto as CPs realizadas por prefeituras do Estado do Paraná se mostram adequadas em relação ao público que pretendem alcançar e o quanto seu objetivo é atingido no que diz respeito à compra efetiva quando comparada aos produtos que solicita.

Neste sentido, este estudo inicia com uma breve contextualização teórico-bibliográfica sobre a relação entre o desenvolvimento regional e os mercados institucionais, especialmente o PNAE, no Paraná, seguindo com 
a metodologia. Na sequência, apresenta-se duas seções de resultados e análises, uma comparando os produtos solicitados nas CPs com os efetivamente adquiridos pelos municípios, e outro discutindo a adequação/eficiência deste método de aquisição de produtos de AFs para a alimentação escolar. Por fim, as conclusões sumarizam este trabalho.

\section{Desenvolvimento Regional e Mercados Institucionais no Paraná}

O Paraná está localizado na Região Sul do Brasil e ocupa uma área de $199.880 \mathrm{~km}^{2}$. Em 2010 totalizou uma população de 10.444 .526 pessoas, e destas apenas 14,7\% moravam no meio rural. O Estado possui 399 municípios divididos em 10 regiões geográficas: Centro Ocidental, Centro Oriental, Centro Sul, Metropolitana de Curitiba, Noroeste, Norte Central, Norte Pioneiro, Oeste, Sudeste e Sudoeste, como pode ser observado no Mapa 1 (INSTITUTO..., 2015). Dado que chama a atenção é que praticamente $80 \%$ dos municípios do Estado têm menos de 20.000 habitantes.

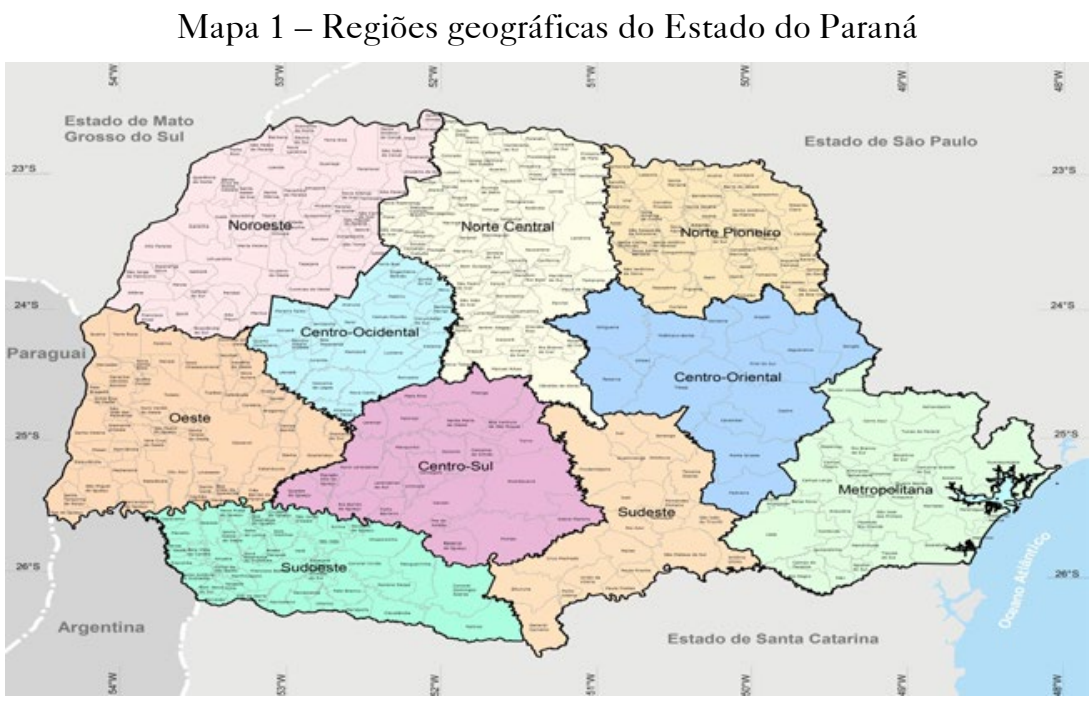

Fonte: Lei Estadual n ${ }^{\circ}$ 15.825/08. Base Cartográfica: INSTITUTO..., 2010. 
O Paraná registra 371.051 estabelecimentos agropecuários. Destes, 302.907 (81,6\%) são caracterizados como agricultura familiar, o que dimensiona a importância destes no cenário estadual. Os dados do censo agropecuário (INSTITUTO..., 2006) mostram que mais de 40\% do valor bruto da produção da agropecuária (VBP-A) do Paraná vem da agricultura familiar, considerando que na mesorregião Sudoeste este porcentual é de 65,9\%.

A análise dos dados de produtos selecionados permite dimensionar a importância da agricultura familiar, em particular na produção de aves, suínos, mandioca e feijão. Ressalte-se também que a produção da agricultura familiar é voltada primordialmente para o abastecimento interno, e que 75,5\% do feijão-preto produzido no Paraná vêm da agricultura familiar, assim como $81 \%$ da mandioca, $43,7 \%$ do milho e $31,2 \%$ da soja. No caso da pecuária, este setor abastece $67,6 \%$ do mercado com a produção de leite, $66,5 \%$ com a produção de aves e 62,2\% com a de suínos (PEREIRA; BAZOTTI, 2010).

A produção primária, porém, se mostra concentrada em poucos produtos e, muitas vezes, dependente de outras indústrias de beneficiamento e venda. Este modelo agroalimentar pode ser considerado um dos motivos pelos quais há a ocorrência, desde a década de 80 do século 20, de um decréscimo populacional substancial nas regiões mais agrícolas, principalmente no meio rural.

Segundo Perondi (2007), tem-se considerado que o esvaziamento populacional seria o principal sintoma de que estas regiões estariam atravessando uma crise social e econômica, sendo a dependência da produção de commodities de grãos agrícolas sua principal causa. O mesmo autor considera que a menor renda per capita nestas regiões se explicaria pelo fato de o setor primário se constituir da maior fonte de remuneração da população e, por sua vez, este ser controlado pelo segmento de abate e industrialização dos produtos, o qual abarcaria a maior parte dos recursos em detrimento dos agricultores - ou seja, fruto de uma relação de monopsônio que se estabelece entre a indústria e os agricultores integrados. 
Com isso, considera-se a importância de buscar estratégias de diversificação econômica e que auxiliem na agregação de valor aos produtos da agricultura familiar, tornando estes produtores mais autônomos e independentes das grandes indústrias de insumos, processadoras e varejistas, e que possam reter maior parcela de recursos dos gêneros produzidos, alcançando mais mercados. Salienta-se, nesta argumentação, a necessidade de acessar novos mercados, adequando a produção da agricultura familiar aos mercados formais e aos novos nichos de mercado consumidor. Estas ações vêm ao encontro de novas percepções de desenvolvimento territorial/rural, ao buscar um processo de transformação produtiva e institucional em um determinado território com a finalidade de reduzir a pobreza e buscar a sua autossustentabilidade.

Van Der Ploeg et al. (2000) destacam a emergência de um novo modelo de desenvolvimento rural com a resposta ao "squeeze" promovido pela modernização da agricultura. Para esses autores, nos anos 90 começa-se a sentir muito fortemente os custos dessa modernização no que se refere às despesas monetárias associadas com o crescimento da necessidade de recursos externos e com tecnologias novas e mais caras, além dos custos de transação e de energia intrínsecos às regulamentações e investimentos obrigatórios. Esse aumento dos custos da produção inviabilizaria a atividade por não compensar os preços de venda, demandando estratégias criativas e inovadoras para diminuir os gastos e otimizar os ganhos.

Nesse sentido, os agricultores buscariam maior autonomia a partir da redefinição de relações e interações com os espaços sociais e o ambiente institucional, buscando formas diversificadas de reação e inovação (WISKERKE; VAN DER PLOEG, 2004). Amin e Cohendet (2004) remetem os processos de inovação e desenvolvimento tecnológico à imersão (embeddedness) em contextos sociais, e a invenção e a criatividade como sendo frutos de um intenso processo de interação e troca de experiências a partir de situações práticas e contingentes. Esses processos seriam, em última instância, soluções criativas e inovadoras que os agricultores utilizariam para enfrentar problemas com- 
plexos. Exemplo disto seriam as estratégias de venda direta ao consumidor de produtos "diferenciados", resultando na agregação de valor ao produto e diminuição dos custos de produção e transação comparativamente ao seu alinhamento às cadeias longas de abastecimento.

É mediante essa complexidade que alguns autores (VAN DER PLOEG et al., 2000; MARSDEN et al., 2000; MARSDEN, 2003) vêm defendendo a mudança paradigmática da modernização para o desenvolvimento rural, em que ele estaria substituindo teórica, prática e politicamente o anterior. As motivações para esse processo estariam nas estratégias, nas práticas, nas identidades, nas políticas, nas instituições e nas novas redes incorporadas ao rural. Assim, as cadeias de abastecimento alimentar projetariam-se como dimensões-chave nos novos padrões emergentes de desenvolvimento rural.

Nesse sentido, passaram a existir nos últimos anos demandas substancias das políticas e programas públicos e institucionais, como o Programa de Aquisição de Alimentos (PAA) e o Programa Nacional de Alimentação Escolar, cujo foco é o produto da agricultura familiar. O Programa de Aquisição de Alimentos foi criado no âmbito do Programa Fome Zero (PFZ), cujas linhas de atuação podem ser sintetizadas em duas: o fortalecimento da agricultura familiar e a garantia da segurança alimentar e nutricional. Nesse sentido, o objetivo principal deste Programa era estimular e fortalecer a agricultura familiar, compreendendo um conjunto de ações relativas à aquisição da produção agropecuária e sua distribuição para grupos de pessoas vulneráveis, além de contribuir para a formação dos estoques estratégicos de alimentos do país (MATTEI, 2007).

Outra iniciativa do governo foi a promulgação da Lei n ${ }^{\circ}$ 11.947/2009, que passa a ser um marco nas políticas públicas relativas à Segurança Alimentar. Em primeiro lugar, porque ampara, explicitamente, a agricultura familiar, tornando obrigatória a utilização de, no mínimo, 30\% do valor remetido às Entidades Executoras (EEs) pelo FNDE na aquisição de gêneros alimentícios desses fornecedores para o PNAE. Em segundo lugar, porque é uma inovação no que diz respeito à legislação das aquisições públicas para 
o PNAE. Se até então todas as compras estavam sob a obrigatoriedade de seguir os preceitos legais de isonomia e concorrência, abre-se um precedente histórico para o fornecedor caracterizado como "agricultor familiar", e, para o mesmo, dispensa-se o processo licitatório, como disposto no seu artigo 14.

Em relação à execução destes Programas no Paraná, verifica-se um avanço substancial em relação ao PNAE e uma paralização em relação ao PAA. Estudos realizados sobre o PNAE (BACCARIN et al., 2015) indicam que a média do porcentual utilizado pelos municípios na compra de produtos da AF em 2014 foi de 26,3\%. Já o porcentual de compra pela Secretaria Estadual de Educação para as escolas estaduais foi de 51,2\%. No mesmo ano, $60 \%$ dos municípios do Paraná usaram mais de 25\% do recurso enviado pelo FNDE para compra de produtos de AFs. Quanto ao PAA, os dados de 2012, relacionados à Região Sul (PR, SC e RS), indicam o alcance de 41.962 agricultores e de 2.977 entidades consumidoras pelos projetos via Conab (PEREZ-CASSARINO et al., 2015). Em 2013, no entanto, foi deflagrada uma operação da Polícia Federal para apurar supostas irregularidades na execução do PAA em alguns projetos do Estado do Paraná, o que culminou na paralização do Programa e reinicio tímido a partir de 2015.

Destaca-se que tanto o PAA quanto o PNAE vêm providenciando resultados positivos na criação de novos mercados para os agricultores familiares (TRICHES; SCHNEIDER, 2010; TRICHES et al., 2014; SILIPRANDI; CINTRÃO, 2014; DELGADO, 2013; MEDEIROS et al., 2011; GHIZELINI, 2010; COSTA, 2010), no entanto ainda estão em fase de implantação e adequação tanto do poder público quanto dos próprios AFs (TRICHES; SCHNEIDER, 2011, ROZENDO; BASTOS; MOLINA, 2014; SOUZA, 2012; BACGARIN et al., 2011; SARAIVA et al., 2013; AVILA; CALDAS; AVILA, 2014; SILIPRANDI; CINTRÃO, 2014; DELGADO, 2013; ME- 
DEIROS et al., 2011) e passando por momentos críticos de contestação, ${ }^{3}$ com reações nem sempre pacíficas aos movimentos de mudança que estão ocasionando (TRICHES; GRISA, 2015).

Estudos demonstram que tentativas bem-sucedidas de realizar compras de alimentos de AFs por parte de escolas e do poder público local, têm a capacidade de proporcionar o abastecimento com baixos custos e promover a produção e circulação de mercadorias, ativando as economias e favorecendo a conexão entre produção e consumo (MORGAN; SONNINO, 2008). Além disso, as compras públicas dos agricultores minimizariam os gastos com transporte, incentivariam a cultura alimentar e a vocação agrícola do local. Finalmente, ao descentralizar e localizar as aquisições públicas, estas se tornariam mais passíveis de controle e regulação social. Neste sentido, destaca-se o papel do Estado como consumidor, e, portanto, incentivador de cadeias de abastecimento consideradas mais sustentáveis.

Seguindo nessa perspectiva, o PAA e o PNAE passariam a apresentar-se com grande potencial para serem utilizados como políticas de caráter estruturante, partindo do princípio de que, ao adquirir gêneros alimentícios de AFs, construir-se-ia uma nova demanda de produção social e ambientalmente mais equilibrada.

Nesta breve descrição do cenário das compras públicas de alimentos e suas potencialidades relativas ao desenvolvimento regional, faz-se necessário que os métodos utilizados para sua viabilidade sejam eficientes. Assim sendo, o processo de aquisições para a alimentação escolar deve ser o mais adequado possível aos AFs e pode ser considerado eficiente quando há retorno total em suas solicitações. Assim, este estudo visa a identificar esta eficiência das CPs a partir da verificação de como estas vêm sendo construídas, e os potenciais problemas que apresentam e que podem prejudicar a efetivação das compras.

\footnotetext{
Segundo texto das autoras, as mesmas relacionam a "operação Agro-Fantasma" e outros acontecimentos ocorridos com o PAA e PNAE com a retórica da intransigência de Hirschman (1992), onde os oposicionistas destas políticas tentam utilizar-se de retóricas perversas, de ameaça e futilidade para minar os processos de mudança.
} 


\section{Procedimentos Metodológicos}

A pesquisa desenvolvida é de caráter quantitativo descritivo. Para efeito deste estudo, selecionaram-se municípios que foram elencados no contexto de uma pesquisa realizada nos Estados de São Paulo, Paraná e Santa Catarina. ${ }^{4}$ As informações foram obtidas mediante fontes documentais, nas quais se analisaram dados secundários (chamadas públicas e prestações de contas) de prefeituras dos municípios do Estado do Paraná (PR) no ano de 2013 (ano anterior ao início da pesquisa supracitada).

Para a escolha dos municípios estipulou-se a priori e por conveniência, uma amostra que alcançasse, no mínimo, 5\% das prefeituras do Estado, tomando-se o cuidado de se estabelecer uma estratificação entre elas de acordo com as macrorregiões e população e de forma que contemplasse cerca de $10 \%$ do alunado. O número de alunos por município foi obtido por intermédio do banco de dados do Instituto Nacional de Pesquisas Educacionais (Inep). Para a caracterização dos municípios utilizou-se a seguinte estratificação: muito pequeno (abaixo de 20.000 habitantes), pequeno (de 20.000 a 100.000 habitantes), médio (de 100.000 a 500.00 habitantes) e grande (acima de 500.000 habitantes), a distribuição entre as macrorregiões e a disponibilidade das chamadas públicas.

Foram utilizadas as CPs do ano de 2013, sendo as mesmas obtidas por meio dos sites das prefeituras e/ou por contato telefônico com os gestores responsáveis pelo PNAE no período de março a agosto de 2014. Foram solicitadas as chamadas públicas de todos os 399 municípios do Paraná, porém conseguiu-se apenas de 26 municípios. Estes estão caracterizados na Tabela 1, segundo a região a qual pertence, população estimada para o

\footnotetext{
4 O presente estudo é decorrente do projeto intitulado "Agricultura Familiar sob a Vigência da Lei Federal 11.947/2009: Abrangência e Adequação das Chamadas Públicas, Impactos na Agricultura Local e Preços Recebidos Pelos Agricultores Familiares nos Estados de São Paulo, Paraná e Santa Catarina” aprovado pela CHAMADA MCTI-CNPq/MDS-SAGI Nº 24/2013 DESENVOLVIMENTO SOCIAL.
} 
ano de 2013, Índice de Desenvolvimento Humano (IDH) e clientela de alunos atendida pelo PNAE no ano de 2014, e também a estratificação por habitantes dos municípios.

Tabela 1 - Características dos municípios do

Estado do Paraná pesquisados no ano de 2013

\begin{tabular}{|c|c|c|c|c|c|}
\hline Município & Região (Ipardes) & $\begin{array}{c}\text { Pop. } \\
\text { Estimada } \\
\text { para } 2013^{*}\end{array}$ & $\begin{array}{c}\text { IDH } \\
2010 * *\end{array}$ & $\begin{array}{c}\text { Clientela } \\
\text { PNAE 2014 } \\
\text { (FNDE) }\end{array}$ & $\begin{array}{c}\text { Estratificação } \\
\text { Municípios }\end{array}$ \\
\hline Antonina & Metropolitana & 19.412 & 0,721 & 2.044 & Muito Pequena \\
\hline Apucarana & Norte Central & 128.058 & 0,748 & 11.035 & Média \\
\hline Assis Chateaubriand & Oeste & 33.988 & 0,729 & 3.282 & Pequena \\
\hline $\begin{array}{c}\text { Boa Esperança do } \\
\text { Iguaçu }\end{array}$ & Sudoeste & 2.763 & 0,700 & 353 & Muito Pequena \\
\hline Capanema & Sudoeste & 19.182 & 0,706 & 2.071 & Muito Pequena \\
\hline $\begin{array}{c}\text { Capitão Leônidas } \\
\text { Marques }\end{array}$ & Oeste & 15.592 & 0,716 & 1.715 & Muito Pequena \\
\hline Carlópolis & Norte Pioneiro & 14.239 & 0,713 & 1.632 & Muito Pequena \\
\hline Cascavel & Oeste & 305.615 & 0,782 & 29.155 & Média \\
\hline Clevelândia & Centro-Sul & 17.501 & 0,694 & 3.041 & Muito Pequena \\
\hline Curitiba & Metropolitana & 1.848 .946 & 0,823 & 133.467 & Grande \\
\hline Dois Vizinhos & Sudoeste & 38.385 & 0,767 & 4.035 & Pequena \\
\hline Francisco Beltrão & Sudoeste & 84.437 & 0,774 & 8.602 & Pequena \\
\hline Guaratuba & Metropolitana & 34.338 & 0,717 & 4.147 & Pequena \\
\hline Inácio Martins & Centro-Sul & 11.282 & 0,600 & 1.723 & Muito Pequena \\
\hline Ivaiporã & Norte Central & 32.699 & 0,730 & 2.147 & Pequena \\
\hline Laranjeiras do Sul & Centro-Sul & 31.936 & 0,706 & 3.374 & Pequena \\
\hline Londrina & Norte Central & 537.566 & 0,778 & 35.029 & Grande \\
\hline Mariópolis & Sudoeste & 6.529 & 0,698 & 681 & Muito Pequena \\
\hline Marmeleiro & Sudoeste & 14.397 & 0,722 & 1.601 & Muito Pequena \\
\hline Medianeira & Oeste & 44.149 & 0,763 & 4.591 & Pequena \\
\hline Mercedes & Oeste & 5.316 & 0,740 & 766 & Muito Pequena \\
\hline Morretes & Metropolitana & 16.325 & 0,686 & 3.046 & Muito Pequena \\
\hline Palmital & Centro-Sul & 14.780 & 0,639 & 2.030 & Muito Pequena \\
\hline Paula Freitas & Sudoeste & 5.700 & 0,717 & 704 & Muito Pequena \\
\hline Sulina & Sudoeste & 3.366 & 0,693 & 287 & Muito Pequena \\
\hline Uraí & Norte Pioneiro & 11.729 & 0,721 & 1.289 & Muito Pequena \\
\hline Total & - & 3.298 .230 & - & 261.847 & - \\
\hline
\end{tabular}

Fonte: Elaborado pelas autoras (2016) com base em dados do IBGE, Ipardes e Inep.

* Instituto Brasileiro de Geografia e Estatística - IBGE (2013).

** Índice de Desenvolvimento Humano - IDH (2010). 
Destaca-se que alguns municípios realizam mais de uma chamada pública por ano; por este motivo justifica-se a análise de $43 \mathrm{CPs}$. Em relação às Prestações de Contas (PCs), estas foram conseguidas mediante o Sistema de Gestão de Prestação de Contas do (SIGPC) no site do FNDE, e foram analisados os seguintes itens relativos a 2013:

a) número de prefeituras que atenderam o determinado pelo artigo $14 \mathrm{da}$ Lei 11.947/2009 e valor efetivamente destinado à compra de produtos da agricultura familiar, segundo as PCs;

b) tipo e quantidade de produtos solicitados pelas CPs e tipo e quantidade de produtos efetivamente comprados, segundo as PCs;

c) adequação das chamadas públicas no que diz respeito às informações sobre periodicidade e pontos de entrega e presença dos preços que seriam pagos por grupo de alimentos.

Quanto ao nível de atendimento do artigo 14, as prefeituras foram classificadas de acordo com os seguintes níveis: não atendimento, atendimento parcial (gasto menor que $30 \%$ com produtos da agricultura familiar), atendimento legal (gasto entre 30 e $40 \%$ com produtos da agricultura familiar), atendimento diferenciado (gasto acima de $40 \%$ com produtos da agricultura familiar).

Quanto ao tipo e quantidade de produto, os mesmos foram verificados por meio das CPs e das notas fiscais, as quais foram consultadas mediante o Sistema de Gestão de Prestação de Contas do (SIGPC) site do FNDE. Os alimentos foram agrupados em: 1) frutas, legumes e verduras; 2) grãos, cereais e tubérculos; 3) leite e derivados; 4) carnes e peixes; 5) panificados; 6) ovos e 7) outros. Dentro do grupo de "outros" foram considerados doces (açúcar mascavo, melado, geleias), vinagre, temperos e molho de tomate, uma vez que os mesmos não se encaixavam nos outros grupos.

Em relação à entrega dos produtos, sua periodicidade foi classificada em: entregas de duas a cinco vezes por semana; entregas semanais; entregas de uma a duas vezes por mês; ou se não constava a informação na chamada 
pública. Já em relação aos pontos de entrega, a logística foi classificada como: muito descentralizada, com mais de 50 unidades de recebimento (UR); descentralizadas, entre 11 e 50 URs; pouco descentralizada, entre 2 e 9 URs; e centralizada, com uma única unidade de entrega.

Após a obtenção dessas informações, os dados quantitativos descritivos foram tabulados e analisados por meio do Programa Estatístico Microsoft Excel $®$ versão 2013.

\section{Que é Solicitado Pelas Chamadas Públicas é Efetivamente Adquirido Pelos Municipios?}

Esta seção trata de identificar se os produtos demandados pelas 43 CPs analisadas foram efetivamente adquiridos e em que medida isso ocorreu. Na Tabela 2 estão dispostas as informações relativas ao recurso repassado pelo FNDE no ano de 2013, os valores das chamadas públicas, os valores realmente destinados à compra de produtos da agricultura familiar e a porcentagem gasta com os produtos da agricultura familiar de cada um dos municípios investigados.

Tabela 2 - Quantidade absoluta e relativa do recurso do FNDE destinado à compra da Agricultura Familiar por município

\begin{tabular}{c|c|c|c|cc}
\hline Município & $\begin{array}{c}\text { Valor } \\
\text { repassado } \\
\text { pelo FNDE }\end{array}$ & $\begin{array}{c}\text { Valor da } \\
\text { Chamada } \\
\text { Pública (CP) }\end{array}$ & $\begin{array}{c}\text { Valor da } \\
\text { Chamada } \\
\text { Pública (CP) }\end{array}$ & $\begin{array}{c}\text { Valor da } \\
\text { Prestação } \\
\text { de Contas }\end{array}$ & $\begin{array}{c}\text { Valor da } \\
\text { Prestação } \\
\text { de Contas }\end{array}$ \\
\hline R $\$$ & $\mathbf{R} \$$ & $\mathbf{\%}$ & $\mathbf{R} \$$ & $\%$ \\
\hline Antonina & $146.940,00$ & - & - & $88.943,90$ & 60,53 \\
\hline Apucarana & $2.013 .092,00$ & $1.217 .632,50$ & 60,48 & $584.005,08$ & 29,01 \\
\hline $\begin{array}{c}\text { Assis } \\
\text { Chateaubriand }\end{array}$ & $319.940,00$ & $217.847,78$ & 68,09 & $213.337,79$ & 66,68 \\
\hline $\begin{array}{c}\text { Boa Esperança } \\
\text { do Iguaçu }\end{array}$ & $30.500,00$ & $19.303,00$ & 63,28 & $5.280,83$ & 17,31 \\
\hline Capanema & $183.920,00$ & $104.023,59$ & 56,55 & $104.501,95$ & 56,82 \\
\hline $\begin{array}{c}\text { Capitão Leônidas } \\
\text { Marques }\end{array}$ & $109.400,00$ & $61.467,15$ & 56,18 & $61.467,15$ & 56,18 \\
\hline Carlópolis & $121.520,00$ & $37.763,50$ & 31,07 & $30.973,00$ & 25,49 \\
\hline
\end{tabular}




\begin{tabular}{c|c|c|c|cc}
\hline Cascavel & $2.810 .852,00$ & - & - & $773.749,80$ & 27,52 \\
\hline Clevelândia & $181.600,00$ & $85.320,36$ & 46,98 & $88.580,86$ & 48,78 \\
\hline Curitiba & $17.735 .088,00$ & $1.415 .168,90$ & 7,97 & $91.919,25$ & 0,52 \\
\hline Dois Vizinhos & $320.660,00$ & $67.007,70$ & 20,89 & $97.210,64$ & 30,31 \\
\hline Francisco Beltrão & $805.960,00$ & $500.590,00$ & 62,11 & $614.466,59$ & 76,24 \\
\hline Guaratuba & $397.860,00$ & $189.826,00$ & 47,71 & $103.028,04$ & 25,9 \\
\hline Inácio Martins & $109.820,00$ & $46.334,00$ & 42,19 & $56.371,48$ & 51,33 \\
\hline Ivaiporã & $330.896,00$ & $293.077,00$ & 88,57 & $39.258,93$ & 11,86 \\
\hline Laranjeiras do & $387.624,00$ & $188.248,40$ & 48,56 & $137.517,17$ & 35,48 \\
\hline Sul & & & & & 8,66 \\
\hline Londrina & $3.987 .528,00$ & $1.961 .498,00$ & 49,19 & $345.433,90$ & 48,29 \\
\hline Mariópolis & $62.600,00$ & $43.761,22$ & 69,90 & $30.231,00$ & 67,40 \\
\hline Marmeleiro & $103.340,00$ & $42.315,00$ & 40,95 & $69.656,27$ & 33,85 \\
\hline Medianeira & $412.580,00$ & $100.576,69$ & 24,38 & $139.661,31$ & 35,24 \\
\hline Mercedes & $61.880,00$ & $20.956,10$ & 33,86 & $21.810,19$ & 30,56 \\
\hline Morretes & $177.760,00$ & $71.752,00$ & 40,36 & $54.330,21$ & 46,87 \\
\hline Palmital & $146.800,00$ & $69.998,89$ & 47,68 & $68.811,44$ & 30,00 \\
\hline Paula Freitas & $54.360,00$ & $15.607,00$ & 28,71 & $16.313,30$ & 42,16 \\
\hline Sulina & $23.120,00$ & $17.626,40$ & 76,23 & $9.747,50$ & 40,61 \\
\hline Uraí & $135.276,00$ & $81.595,75$ & 60,32 & $54.940,94$ & $12,52 \%$ \\
\hline Total & $31.170 .916,00$ & $6.859 .296,93$ & $22 \%$ & $3.901,548,52$ & \\
\hline & & & & & \\
\hline
\end{tabular}

Fonte: Elaborado pelas autoras 2016 com base em dados do Fundo Nacional de Desenvolvimento da Educação, 2013 e nas CPs disponibilizadas pelos municípios.

De acordo com os dados, verifica-se que a soma dos recursos repassados pelo FNDE para os municípios no ano de 2013 equivale a um montante de $\mathrm{R} \$ 31.170 .916,00$. Deste valor, $\mathrm{R} \$ 6.859 .296,93$ foram solicitados pelas CPs (22\%), mas apenas $\mathrm{R} \$ 3.901,548,52$ (12,52\%) foram efetivamente pagos aos AFs. Vale ressaltar que dois $(7,69 \%)$ dos 26 municípios pesquisados não apresentavam os valores de seus itens nos editais de chamada pública. Dos 24 que apresentaram valores, 13 locais (50\%) adquiriram menos do que solicitaram nas CPs, $10(38,46 \%)$ adquiriram mais do que constavam nestes editais, e somente um município $(3,84)$ adquiriu a mesma quantia que solicitou. 
Em relação ao atendimento ao artigo 14 da Lei 11.947/2009, ao analisar os 26 municípios pode-se perceber que $12(46,15 \%)$ tiveram um atendimento diferenciado, pois adquiriram mais de $40 \%$ da agricultura familiar e $6(23,07$ $\%$ ), adquiriram entre $30 \%$ e $40 \%$ da agricultura familiar. Assim, praticamente $70 \%$ dos municípios investigados cumpriram a legislação. Por outro lado, oito municípios $(30,76 \%)$, tiveram um atendimento apenas parcial, pois não adquiriram o mínimo de $30 \%$ dos produtos da agricultura familiar conforme estabelecido pela legislação do PNAE. Esta amostra, no entanto, não reflete exatamente os dados do Estado como um todo. Segundo o FNDE (BRASIL, 2016), no ano de 2013 dos 399 municípios paranaenses, cerca de 124 (31\%) adquiriram mais de $30 \%$ de alimentos da agricultura familiar para a alimentação escolar, e destes, 50 municípios (12\%) adquiriram mais de $40 \%$ em produtos da agricultura familiar.

Os dados encontrados aproximam-se mais da realidade da Região Sudoeste do Paraná, onde o estudo de Gregolin, Gregolin e Zonin (2013) verificou, em 2013, que, dentre os 42 municípios desta região, 28 (66,66\%) deles atingiram ou ultrapassaram a porcentagem mínima de $30 \%$ que é estipulada na Lei, sete $(16,66 \%)$ não atingiram a porcentagem mínima e um $(2,38 \%)$ não adquiriu nenhum produto provindo da agricultura familiar, come seis municípios $(14,28 \%)$ não informando o valor.

Como citado anteriormente, houve diferença entre o valor total solicitado de produtos da AF pelas CPs e o valor efetivamente pago, segundo as PCs. Para aprofundar um pouco mais a análise, no Gráfico 1 estão representadas as quantidades que foram demandadas, e as quantidades realmente compradas de alimentos para a alimentação escolar relativas aos grupos alimentares que estavam descritas nas chamadas públicas analisadas e as quantidades que estavam presentes nas prestações de contas. 
Gráfico 1 - Porcentual por grupo de alimentos, considerando a quantidade em quilos, solicitados nas Chamadas Públicas e quantidades em quilos adquiridas nas Prestações de Contas

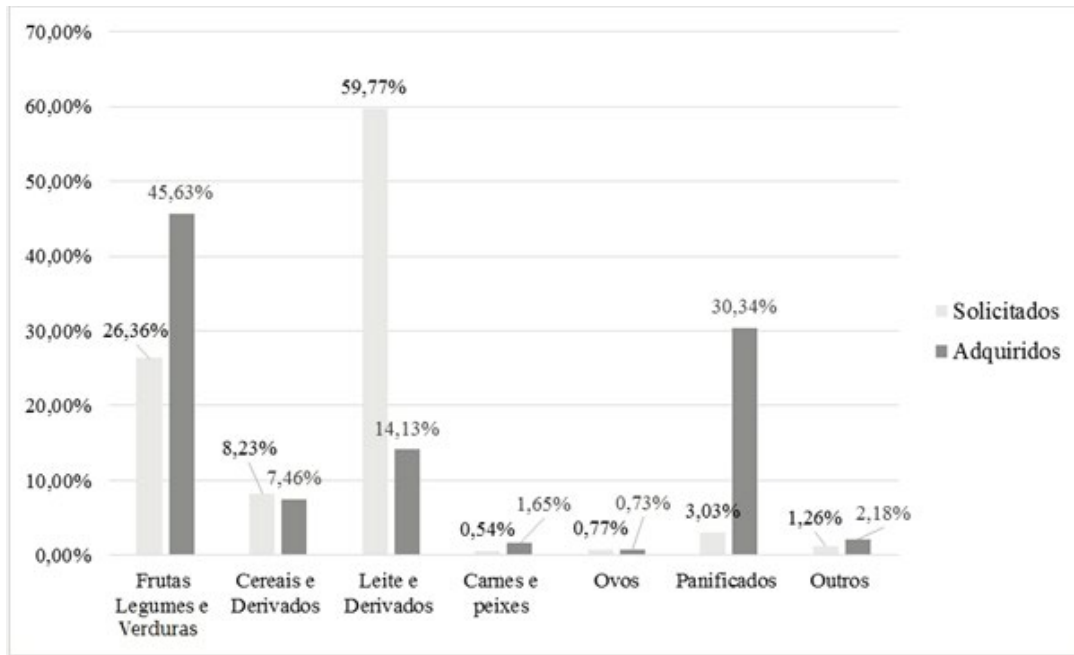

Fonte: Elaborado pelas autoras (2016) com base nas Chamadas Públicas (2013) e nas Prestações de Conta (2013) dos municípios pesquisados.

Analisando os produtos que foram solicitados mediante as chamadas públicas, verificou-se uma grande diferença em relação ao que foi adquirido. Observa-se que nas CPs o primeiro grupo mais solicitado é o de laticínios $(59,77 \%)$, seguido pelo de frutas, legumes e verduras $(26,36 \%)$, depois cereais e derivados $(8,23 \%)$. Já em relação aos produtos realmente adquiridos, os quais foram analisados por meio das PCs, concluiu-se que os mais comprados foram frutas, legumes e verduras $(45,63 \%)$, seguidos pelos panificados $(30,34 \%)$, leite e derivados $(14,13 \%)$ e cereais e derivados $(7,46 \%)$.

Verificando os produtos reivindicados e os realmente comprados, pôde-se perceber que, no geral, as prefeituras demandaram alguns tipos de alimentos mas compraram outros. Estas ocorrências podem ser explicadas ao se considerar que a produção de frutas, legumes e verduras e produtos minimamente processados, já são culturas estabelecidas pelos agricultores familiares e, portanto, mais passíveis de oferta pelos mesmos. Além disso, 
não necessitam de maiores adequações aos padrões exigidos de certificação e inspeção, como acontece com produtos mais processados e de origem animal (RIBEIRO; CERATTI; BROCH, 2013).

É o que acontece no caso dos laticínios, que, embora sejam muito demandados, os agricultores familiares não conseguem fornecê-los, pois se exige maior fiscalização. Amorin e Staduto (2008) citam que as dificuldades que os agricultores têm em relação à legalização do seu empreendimento para colocar os produtos no mercado regional, nacional e até internacional, prejudicam a produção e comercialização destes produtos. Triches e Schneider (2010) expõem que, entre as dificuldades enfrentadas na aquisição de alimentos da agricultura familiar para o Programa de Alimentação Escolar, estão as exigências sanitárias e de qualidade, como os registros de inspeção, cadastros e alvarás do estabelecimento, entre outros, e muitas vezes os agricultores deixam de comercializar seus produtos por falta dessas adequações.

Outro grupo que também se destacou foi o dos panificados, pois nas chamadas públicas foram solicitados somente $3,03 \%$, porém, ao analisar o que realmente foi comprado, verificou-se um porcentual de 30,34\%. Supõem-se que este grupo esteja ocupando cada vez mais espaço nas aquisições de AFs por terem maior valor agregado se comparado ao grupo de frutas e hortaliças, gerando mais renda, além de não dependerem de condições climáticas para serem produzidos. Fica difícil explicar, no entanto, porque não foram solicitados nas CPs. Pode-se deduzir que os mesmos foram comprados por processos licitatórios, ou por dispensa dos mesmos, sem o uso deste instrumento de compra.

Também analisou-se estas diferenças a partir do montante de recurso solicitado e despendido para a aquisição de produtos da AF. No Gráfico 2 estão dispostos os porcentuais dos recursos provenientes do FNDE destinados aos pedidos dos produtos e os que realmente foram comprados. 
Gráfico 2 - Porcentagem do recurso do FNDE solicitado por categoria de alimentos nas Chamadas Públicas e nas Prestações de Contas

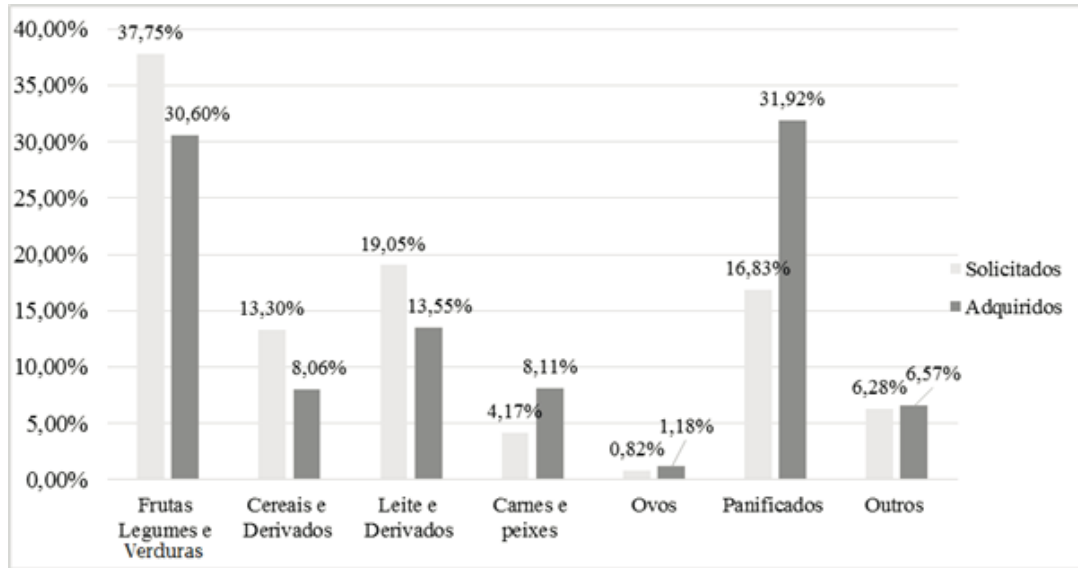

Fonte: Elaborado pelas autoras, 2016.

Em relação aos recursos demandados para a compra dos alimentos, verificou-se que nas chamadas públicas o maior volume de recursos deveria ser para pagar frutas, legumes e verduras $(37,75 \%)$, leite e derivados $(19,05 \%)$ e panificados $(16,83 \%)$, respectivamente. Nas prestações de contas, no entanto, verificou-se que os grupos onde se gastou mais recursos foram os panificados $(31,92 \%)$, seguido das frutas, legumes e verduras $(30,60 \%)$ e leite e derivados (13,55\%). Estes dados demonstram o que foi observado anteriormente, no sentido de que há uma solicitação maior de laticínios, mas que a sua compra é frustrada e que os panificados superam as solicitações de frutas, legumes e verduras no que se refere ao recurso utilizado.

Pode-se perceber que, ao somar os recursos utilizados para a compra de panificados, leite e derivados, carnes e peixes, estes representaram aproximadamente $54 \%$ dos recursos, ou seja, $\mathrm{R} \$ 571.323,29$. Isso demonstra o quanto estes produtos possuem maior valor agregado quando comparados aos produtos de origem vegetal in natura. Wesz Junior (2009) acrescenta que a agroindustrialização também foi uma forma de algumas propriedades familiares permanecerem no campo, aumentando a diversificação das atividades. 
Quanto à origem dos produtos, verificou-se que 24 chamadas $(55,81 \%)$ apresentavam produtos de origem animal, 42 chamadas $(97,67 \%)$ apresentavam produtos de origem vegetal, e em uma chamada (2,32\%) não constava nenhum alimento. Estes dados corroboram com os encontrados por Baccarin et al. (2011), que ao analisarem as chamadas públicas do Estado de São Paulo, observaram que em todas elas constavam produtos de origem vegetal e apenas $58,54 \%$ delas solicitavam produtos de origem animal.

Tais resultados demonstram que nem sempre os produtos solicitados pelas CPs têm sido adquiridos pelas prefeituras, e, nesta pesquisa, apenas pouco mais da metade dos quantitativos solicitados foram efetivados. Ainda, observou-se divergências entre os produtos e suas respectivas quantidades e valores quando comparados às solicitações das CPs e os registros das PCs. Isto remete a segunda questão-chave a ser respondida neste trabalho: Será que as chamadas públicas estão sendo formuladas de forma a serem adequadas ao público e aos produtos a que se destinam?

\section{Adequação das Chamadas Públicas ao Público e Produtos da Agricultura Familiar}

Baccarin et al. (2011) verificaram inúmeras inadequações nas CPs de São Paulo, como a solicitação de produtos nem sempre condizentes com a produção da AF e o elevado número de pontos de entrega e periodicidade das mesmas. Neste estudo buscou-se identificar estas questões e observou-se que, em relação à periodicidade de entrega dos produtos, 93\% das CPs não apresentavam esta informação ou a mesma estava incompleta. Nas chamadas que constavam estes dados, em duas a entrega era semanal e em três as entregas eram de três a cinco vezes por mês. Isso demonstra que os editais de CPs estão incompletos, o que dificulta a entrega dos agricultores, pois os mesmos não conseguem se organizar e garantir a regularidade da produção e a eficiência da logística. 
Se comparado com o estudo de Baccarin et al. (2012), em que apenas 16,6\% das chamadas analisadas não definiam a periodicidade das entregas, o número de omissão desta informação no Paraná (93\%) é bem superior. Em outro estudo, Baccarin et al. (2011), ao analisarem editais dos anos de 2010 e 2011 em São Paulo, perceberam que em 56\% das chamadas a previsão da entrega dos produtos era semanal. Isso aparenta ser adequado às condições de agricultores que produzem produtos in natura, como frutas, verduras e legumes. Dos editais, $31,71 \%$, no entanto, não traziam esta informação. $\mathrm{Ou}$ seja, o agricultor somente terá real ciência de sua possibilidade de distribuição após sua habilitação, o que implicará em menor tempo de planejamento para suas atividades. Para os autores supracitados, uma possibilidade para maior adequação aos agricultores exige melhor elaboração das CPs, com a presença de cronogramas descritivos com datas e quantidades estipuladas nas entregas.

Em relação ao número de unidades de recebimento, $72 \%$ das CPs apresentavam 1 unidade de recebimento, 7\% apresentavam de 11 a 50 unidades de recebimento e $21 \%$ não apresentavam a informação ou a mesma estava incompleta. Na comparação com o estudo de Baccarin et al. (2012), em que em 47,9\% dos editais analisados a entrega era em uma única unidade de recebimento (em almoxarifados centrais ou cozinhas pilotos das prefeituras), os editais paranaenses têm sido mais condizentes com a questão logística dos AFs. Neste cenário, é passível supor que o agricultor ou organização familiar consiga cumprir suas responsabilidades de entrega, planejar melhor as questões logísticas e de transporte e ainda atender à distribuição dos alimentos para as escolas do município.

É importante considerar que o Artigo 14 e suas regulamentações até 2013 previam que os recursos da Alimentação Escolar deveriam pagar apenas os gêneros alimentícios; por este motivo não se permitia a inclusão de fretes e outros serviços que poderiam estar vinculados com a distribuição dos alimentos (BACCARIN et al., 2011). Neste sentido, um número elevado de locais de entrega era considerado um obstáculo para os agricultores, especialmente 
para aqueles que atuavam individualmente. Neste quesito, a legislação referente à Resolução n ${ }^{\circ}$ 26/2013, no seu artigo 29, passou a indicar que estes custos poderiam ser previstos na definição dos preços para aquisição dos AFs.

Segundo Guilhoto et al. (2006), a logística de distribuição e comercialização da produção agropecuária não é simples, requerendo, assim, procedimentos com alto nível de organização, o que pode influenciar decisivamente no sucesso ou fracasso de uma atividade. Por este motivo, quanto mais centralizada a entrega dos produtos dos agricultores familiares, maiores seriam as chances de propiciar efeitos benéficos e continuados em sua renda e, por conseguinte, no desenvolvimento local (BACCARIN et al., 2011).

Em relação aos preços a serem pagos aos AFs, verificou-se que $93 \%$ das CPs apresentavam esta informação. Nesse sentido, observa-se que nem todos os municípios entendiam que os preços a serem pagos eram itens obrigatórios nas CPs, conforme dita o parágrafo terceiro do artigo 29 da Resolução 26/2013. Sem esta informação, o agricultor não tem condições de saber se vale a pena participar destes chamamentos do ponto de vista econômico, reduzindo o seu interesse em participar.

Estes dados demonstram que este instrumento de compra ainda precisa de ajustes e que nem todas as EEs têm conseguido elaborá-lo, tornando-o ineficiente para a sua finalidade. Informações detalhadas sobre a logística, periodicidade de entrega e preços pagos, são essenciais para que os AFs tenham mais interesse em participar destas aquisições e possam se organizar para efetuar a oferta de forma regular, tornando esta política mais efetiva no alcance dos seus objetivos.

\section{Conclusão}

Verificou-se, a partir deste estudo, que em relação aos recursos provindos do FNDE cerca de $70 \%$ dos municípios destinam $30 \%$ ou mais para a compra de produtos da agricultura familiar. Como visto, no entanto, a 
demanda de produtos que constavam nas chamadas públicas dos municípios analisados não foi efetivada totalmente. Do total remetido pelo FNDE aos municípios pesquisados, $22 \%$ foi direcionado à aquisição de produtos da AF via chamadas públicas, mas apenas pouco mais da metade foi realmente paga aos AFs.

Isto remete a possíveis problemas na sua adequação aos AFs e na sua eficiência enquanto instrumento de aquisição de produtos. Dessa forma, apesar de todos os avanços que o PNAE teve ao longo dos anos, ainda existem inadequações em sua execução no que respeita a estas aquisições, o que pode explicar, em parte, a baixa adesão no número de AFs que participam como fornecedores, especificamente no Paraná (GREGOLIN, 2016b).

Neste sentido, este estudo evidenciou vários problemas relativos às chamadas públicas no que diz respeito às informações que elas devem apresentar, como o preço dos produtos, logística e periodicidade de entrega, prejudicando sua eficiência como instrumento de aquisição pública. Estas evidências sugerem que, se estes instrumentos fossem melhorados, o PNAE poderia alcançar com mais efetividade os seus objetivos de promover alimentação de qualidade e desenvolvimento sustentável, adquirindo mais produtos da AF.

Outro ponto que pode ser destacado neste estudo é a dificuldade em encontrar informações acerca da aquisição de gêneros alimentícios para o PNAE, uma vez que a maioria das prefeituras não disponibiliza em seus sites as CPs. Este fato remete à baixa publicidade das mesmas para que os próprios AFs tenham conhecimento sobre elas, prejudicando ainda mais a sua adesão. Além disso, o baixo número de CPs analisadas é um limitante desta pesquisa, posto que os dados poderiam ser mais representativos do Estado do Paraná, prejudicando, assim, uma maior validade externa deste estudo.

Por fim, este estudo destaca a importância da realização de mais pesquisas que possam investigar mais a fundo quais são as dificuldades dos gestores públicos em elaborarem corretamente as CPs e quais os empecilhos 
identificados pelos AFs neste sentido, com o intuito de tornar instrumento eficiente, principalmente para viabilizar cada vez mais o acesso destes últimos aos mercados institucionais.

\section{Referências}

AMORIN, L. S. B.; STADUTO, J. A. R. Desenvolvimento territorial rural: a agroindústria familiar no oeste do Paraná. Revista de Economia Agrícola, São Paulo, v. 55, n. 1, p. 15-29, jan./jun. 2008.

AMIN, A.; COHENDET, P. Architectures of Knowledge: Firms, Capabilities and Communities. New York: Oxford, 2004.

AVILA, M. L.; CALDAS, E. L.; AVILA, S. R. Coordenação e efeitos sinérgicos em políticas públicas no Brasil: o caso do Programa de Aquisição de Alimentos e do Programa Nacional de Alimentação Escolar. In: MINISTÉRIO DO DESENVOLVIMENTO SOCIAL E COMBATE À FOME. PAA: 10 anos de aquisição de alimentos. Brasília: MDS, 2014. p. 96-113.

BACCARIN, J. G. et al. Alimentação escolar e agricultura familiar: alcance e dificuldades para implantação do artigo 14 da Lei 11947/2009 no Estado de São Paulo. In: CONGRESSO DA SOBER, 49., 2011, Belo Horizonte. Disponível em: <www. fcav.unesp.br/Home/departamentos/economiarural/.../artigo-anais.docx $>$. Acesso em: 19 set. 2015.

. Agricultura familiar sob a vigência da Lei Federal 11.947/2009: abrangência e adequação das chamadas públicas, impactos na agricultura local e preços recebidos pelos agricultores familiares. Projeto de Pesquisa Tecnológica e Científica, Jaboticabal, SP, 2012.

BELIK, W.; CHAIM, N. A. O programa nacional de alimentação escolar e a gestão municipal: eficiência administrativa, controle social e desenvolvimento local. Revista de Nutrição, v. 22, p. 595-607, 2009.

BRASIL. Fundo Nacional de Desenvolvimento da Educação (FNDE). Alimentação escolar, histórico. Disponível em: <http://www.fnde.gov.br/index.php/ae-historico>. Acesso em: 31 out. 2015.

. Fundo Nacional de Desenvolvimento da Educação (FNDE). Alimentação escolar. Dados estatísticos. 2016. Disponível em: <http://www.fnde.gov.br/programas/ alimentacao-escolar>. Acesso em: 21 jan. 2016.

. Lei n. 11.947, de 16 de junho de 2009. Dispõe sobre o atendimento da alimentação escolar e do Programa Dinheiro Direto na Escola aos alunos da educação básica; altera as Leis nos 10.880, de 9 de junho de 2004, 11.273, de 6 de fevereiro de 2006, 11.507, de 20 de julho de 2007; revoga dispositivos da Medida Provisória no 2.178-36, de 24 de agosto de 2001, e a Lei no 8.913, de 12 de julho de 1994; e dá outras providências. Diário Oficial da União, Brasília, n. 113, p. 2-4, jun. 2009. Disponível em: <http://www.planalto.gov.br/ccivil_03/_ato2007-2010/2009/lei/111947. htm>. Acesso em: 10 jan. 2015. 
COSTA, I. B. “Nesta terra, em se plantando tudo dá?” Política de soberania e segurança alimentar e nutricional no meio rural paranaense, o caso do PAA. 2010. Tese (Doutorado em Desenvolvimento Regional) - UFRN, Programa de Pós-Graduação em Ciências Sociais (PPGCS), Natal, RN, 2010.

DELGADO, G. C. Relatório de avaliação do PAA - III Síntese. Brasília, 2013.

GHIZELINI, A. A. M. Atores sociais, agricultura familiar camponesa e o espaço local: uma análise a partir do Programa de Aquisição de Alimentos. 2010. Tese (Doutorado em Sociologia) - UFPR, Programa de Pós-Graduação em Sociologia (PPGS), Curitiba, PR, 2010.

GREGOLIN, G. C. et al. Participation of family agriculture as a provider of school meals in the territory southwest of the Paraná. Nucleus, Ituverava, on-line, v. 13, p. 169-184, 2016a. Disponível em: <http://www.nucleus.feituverava.com.br/index.php/ nucleus/article/view/1480/1968>. Acesso em: 20 jan. 2016.

. Alimentação escolar e agricultura familiar: a implementação da Lei 11.947/2009 e seu caráter sustentável no Sudoeste no Paraná. 2016. Dissertação (Mestrado em Desenvolvimento Rural Sustentável) - Universidade Estadual do Oeste do Paraná, Unioeste, Programa de Pós-Graduação em Desenvolvimento Rural Sustentável (PPGDRS), General Cândido Rondon, PR, 2016b.

GREGOLIN, G. C.; GREGOLIN, M. R. P.; ZONIN, W. J. O encontro da produção orgânica familiar com a alimentação escolar no Território Sudoeste do Paraná: desempenho e dificuldades sob a ótica dos gestores municipais. In: JORNADA QUESTÃO AGRÁRIA E DESENVOLVIMENTO: PROJETOS SOCIAIS E POLÍTICAS PÚBLICAS EM DISPUTA, 2., 2013, Curitiba. Anais... Curitiba, 2013.

GUILHOTO, J. J. M. et al. A importância do agronegócio familiar no Brasil. Revista de Economia e Sociologia Rural, v. 44, n. 3, set. 2006.

HIRSCHMAN, Albert O. A retórica da intransigência: perversidade, futilidade, ameaça. São Paulo: Companhia das Letras, 1992.

ÍNDICE DE DESENVOLVIMENTO HUMANO (IDH). Índice de Desenvolvimento Humano dos Municipios Paranaenses. 2010. Disponível em: <http://www.br.undp.org/ content/brazil/pt/home/idh0/rankings/idhm-municipios-2010.html>. Acesso em: 25 fev. 2016.

INSTITUTO BRASILEIRO DE GEOGRAFIA E ESTATÍSTICA (IBGE). Censo Agropecuário. 2006. Disponível em: <http://www.ibge.gov.br/home/estatistica/economia/agropecuaria/censoagro/2006/>. Acesso em: 28 jan. 2016.

. Cidades. 2013. Disponível em: <http://www.cidades.ibge.gov.br/xtras/uf.ph p? lang $=\& \operatorname{coduf}=41 \&$ search $=$ parana $>$. Acesso em: 28 fev. 2016.

INSTITUTO DE TERRAS, CARTOGRAFIA E GEOCIÊNCIAS (ITCG). 2010. Disponível em <www.itcg.pr.gov.br>. Acesso: 10 jan. 2017.

INSTITUTO NACIONAL DE ESTUDOS E PESQUISAS EDUCACIONAIS ANÍSIO TEIXEIRA (INEP). Clientela Atendida no Programa Nacional de Alimentação Escolar (PNAE). 2014. Disponível em <http:/www.fnde.gov.br/pnaeweb/publico/ relatorioDelegacaoEstadual.do>. Acesso em: 15 jan. 2016. 
INSTITUTO PARANAENSE DE DESENVOLVIMENTO ECONÔMICO E SOCIAL (Ipardes). Paraná em números. 2015. Disponível em: <http://www.ipardes. gov.br/index.php?pg_conteudo=1\&cod_conteudo=1>. Acesso em: 27 fev. 2016.

IZUMI, B.; ALAIMO, K.; HAMM, M. Farm to school programs: Exploring the role of regionally-based food distributors in alternative agri food networks. Agr Hum Values, 27(3), p. 335-350, 2010.

MARSDEN, T. K. et al. Food supply chain approaches: exploring their role in rural development. Sociologia Ruralis, v. 40, p. 424-438, 2000.

MARSDEN, T. K. The condition of rural sustainability. Assen, The Netherlands: Van Gorcun, 2003.

MATTEI, L. Programa de aquisição de alimentos da agricultura familiar (PAA): antecedentes, concepção e composição geral do Programa. Cadernos do CEAM, UnB, v. 7, p. 33-44, 2007.

MEDEIROS, L. S. et al. O Programa de Aquisição de Alimentos (PAA) em assentamentos de reforma agrária: implantação, impactos e perspectivas. Rio de Janeiro, RJ, 2011. (Relatório de pesquisa).

MINISTÉRIO DA EDUCAÇÃOA. Fundo Nacional do Desenvolvimento da Educação. Valores investidos na aquisição de gêneros alimentícios diretamente da agricultura familiar para o PNAE. Exercício do ano de 2013. Disponível em: <http://www.fnde. gov.br/programas/alimentacao-escolar/alimentacao-escolar-consultas/dados-da-agricultura-familiar>. Acesso em: 13 jun. 2016.

MINISTÉRIO DO DESENVOLVIMENTO SOCIAL E DE COMBATE A FOME (MDS). Secretaria de Avaliação e Gestão da Informação (Sagi). Grupo Gestor. Balanço de avaliação da execução do Programa de Aquisição de Alimentos (PAA) 2003 a 2010. Relatório descritivo. Brasília, 2010. Disponível em: <http://goo.gl/tyXx87>. Acesso em: 30 out. 2015.

MORGAN, K.; SONNINO, R. The school food revolution. London: Earthscan, 2008. PEREIRA, V. V. R.; BAZOTTI, A. Ruralidade, agricultura familiar e desenvolvimento - nota técnica. Ipardes, Curitiba, n. 16, 2010. Disponível em: <http://www. ipardes.gov.br/biblioteca/docs/NT_16_ruralidade_agric_familiar_desenv.pdf $>$ Acesso em: 25 nov. 2015.

PEREZ-CASSARINO, J. et al. A promoção da soberania e segurança alimentar e nutricional por meio do mercado institucional: a experiência brasileira. In: BEZERRA, I.; PEREZ CASSARINO, J. (Org.). Soberania alimentar e segurança alimentar e nutricional na America Latina e Caribe. 1. ed. Curitiba: Ed. UFPR, 2015. p. 223-246. V. 1.

PERONDI, M. A. Diversificação dos meios de vida e mercantilização da agricultura. 2007. Tese (Doutorado em Desenvolvimento Rural) - UFRGS, Programa de Pós-Graduação em Desenvolvimento Rural (PPGDR), Porto Alegre, RS, 2007.

RIBEIRO, A. L. de P.; CERATTI, S.; BROCH, D. T. Programa Nacional de Alimentação Escolar (PNAE) e a participação da agricultura familiar em municípios do Rio Grande do Sul. Revista Gestão e Desenvolvimento em Contexto-Gedecon, vol. 1, n. 1, 2013.

ROZENDO, C.; BASTOS, F. B. C.; MOLINA, W. S. L. A implementação das novas diretrizes do PNAE: desafios institucionais. In: ENCONTRO DA REDE DE ESTUDOS RURAIS, 6., 2014, Campinas. Disponível em: <revista.fct.unesp.br/index. php/nera/article/download/3569/2904>. Acesso em: 15 fev. 2015. 
SARAIVA, E. B. et al. Panorama da compra de alimentos da agricultura familiar para o Programa Nacional de Alimentação Escolar. Ciência \&̊ Saúde Coletiva, 18(4), p. 927-936, 2013.

SILIPRANDI, E.; CINTRÃO, R. As mulheres agricultoras no Programa de Aquisição de Alimentos. In: MINISTÉRIO DO DESENVOLVIMENTO SOCIAL E COMBATE À FOME. PAA: 10 anos de aquisição de alimentos. Brasília: MDS, 2014. p. 114-152.

SOARES, F. V. et al. Structured Demand and Smallholder Farmers in Brazil: the Case of PAA and PNAE. Brasília: IPC; WFP, 2013.

SOUZA, L. B. B. Organizações da Agricultura Familiar no Estado de São Paulo e sua experiência de fornecimento para o PNAE. In: Projeto Nutre SP: análise da inclusão da agricultura familiar na alimentação escolar no Estado de São Paulo. São Paulo: Instituto Via Pública, 2012.

TRICHES, R. M.; SCHNEIDER, S. Reconstruindo o "elo perdido": a reconexão da produção e do consumo de alimentos através do Programa de Alimentação Escolar no município de Dois Irmãos (RS). Segurança Alimentare Nutricional, 17(1), p. 1-15, 2010.

. Desestruturar para construir: interfaces para a agricultura familiar acessar o programa de alimentação escolar. Estudos Sociedade e Agricultura. Rio de Janeiro, vol. 20, n. 1, p: 66-105, 2011.

TRICHES, R. M.; GRISA, C. Entre mudanças e conservadorismos: uma análise dos Programas de Aquisição de Alimentos (PAA e PNAE) a partir da retórica de intransigência. Revista Nera, Unesp, v. 26, p. 10-27, 2015.

TRICHES, R. M. et al. O Programa de Alimentação Escolar nutrindo o desenvolvimento: ideias e relações inovadoras. In: SCHNEIDER, S. et al. (Org.). Sementes $e$ brotos da transição: inovação, poder e desenvolvimento em áreas rurais do Brasil. 1. ed. Porto Alegre: UFRGS, 2014. p. 115-139. V. 1.

TURPIN, Maria Elena. A alimentação escolar como fator de desenvolvimento local por meio do apoio aos agricultores familiares. Segurança Alimentare Nutricional, Campinas, v. 16, n. 2, p. 20-42, 2009.

VAN DER PLOEG, J. D. et al. Rural development: from practices and policies towards theory. Sociologia Ruralis, v. 40, p. 392-408, 2000.

VILLAR, B. S. et al. Situação dos municípios do Estado de São Paulo com relação à compra direta de produtos da agricultura familiar para o Programa Nacional de Alimentação Escolar (PNAE). Revista Brasileira de Epidemiologia, v. 16, p. 223-226, 2013.

WESZ JUNIOR, V. J. Novas configurações no meio rural brasileiro: uma análise a partir das propriedades com agroindústria familiar. Agroalimentaria, v. 15, n. 28, p. 25-34, jan./jun. 2009.

WISKERKE, J. S. C.; VAN DER PLOEG, J. D. Seeds of Transition: essays on novelty production, niches and regimes in agriculture. Assen: Royal van Gorcum, 2004.

WORLD FOOD PROGRAME. Global School Feedind Report. Rome: World Food Programme, 2009. 